\title{
sciendo
}

\section{The Honest Weasel A Guide for Successful Weaseling}

\author{
Patrick Dieveney \\ California State University \\ DOI: $10.2478 /$ disp-2020-0002 \\ BIBLID [0873-626X (2020) 56; pp.41-69]
}

\begin{abstract}
Indispensability arguments are among the strongest arguments in support of mathematical realism. Given the controversial nature of their conclusions, it is not surprising that critics have supplied a number of rejoinders to these arguments. In this paper, I focus on one such rejoinder, Melia's 'Weasel Response'. The weasel is someone who accepts that scientific theories imply that there are mathematical objects, but then proceeds to 'take back' this commitment. While weaseling seems improper, accounts supplied in the literature have failed to explain why. Drawing on examples of weaseling in more mundane contexts, I develop an account of the presumption against weaseling as grounded in a misalignment between two types of commitments. This is good news to the weasel's opponents. It reinforces that they were right to question the legitimacy of weaseling. This account is also beneficial to the weasel. Uncovering the source of the presumption against weaseling also serves to draw out the challenge that the weasel must meet to override this presumption — what is required to be an 'honest weasel'.
\end{abstract}

\section{Keywords}

Mathematical realism, indispensability, weaseling, commitments, ontology.

\section{Introduction}

Indispensability arguments continue to occupy center stage in the philosophy of mathematics. While there are many versions of these arguments, they share the same underlying structure. According to these arguments, we are committed to the existence of mathematical objects insofar as reference to these objects is indispensable to science. We are committed to the existence of things like numbers, 
sets, functions, etc. Many philosophers find this conclusion unacceptable, and there are numerous responses to these arguments. ${ }^{1}$ Here I want to consider one response that has drawn considerable attention, Joseph Melia's 'Weasel Response'.

The core of The Weasel Response to indispensability arguments is the activity of weaseling. This occurs when someone makes assertions that, by their own admission, imply that they are committed to the existence of certain objects, but they so-to-speak 'take back' this commitment. In the present context, the weasel is someone who openly admits that our best scientific theories imply that there are mathematical objects, that references to these objects are indispensable, but nonetheless denies that there are mathematical objects. The weasel takes back ontological commitment to such objects.

Melia argues that not only is weaseling something that scientists engage in, it is something that (in some cases) they must engage in to accurately express their views. In some cases, we cannot adequately express certain scientific claims without referring to mathematical objects. ${ }^{3}$ To the extent that this is true, weaseling seems an attractive response to indispensability arguments. While many opponents of indispensability arguments have been mired in the difficult task of attempting to show that, contrary to appearances, mathematical objects are actually dispensable to scientific theories, the weasel sidesteps this troubling debate. She simply concedes the point and nonetheless weasels out of the implied ontological commitments.

\footnotetext{
${ }^{1}$ See, for example, Sober 1993, Maddy 1992, 1997, Leng, 2002, Saatsi 2011, and Pincock 2004.

${ }^{2}$ See Melia 2000.

${ }^{3}$ Melia suggests that weaseling is something that scientists (or, at least, nominalist scientists) must sometimes engage in given our linguistic limitations. He considers, for example, two ways in which we might express spatio-temporal relations between physical objects. One way would be to accept as primitive infinitely many two-place predicates, " $\mathrm{x}$ is 1-meter-from $\mathrm{y}$ ", "x is 1.1-meters-from $y$ ", " $\mathrm{x}$ is 1.11-meters from y", and so forth. Another way would be to include a single three-place predicate " $\mathrm{x}$ is $\mathrm{r}$ meters from $\mathrm{y}$ ", where " $\mathrm{r}$ " ranges over real numbers. The former requires accepting a language that not only contains infinitely many primitive twoplaced predicates, it requires uncountably many of these primitive predicates. Consequently, it is unsurprising that we adopt the latter and express spatio-temporal relations in a way that refers to mathematical objects. (See Melia 2000: 472-3.)
} 
Given that The Weasel Response has the appearance of theft over honest toil, it is not surprising that this response to indispensability arguments has been met with a number of rejoinders. In this paper, I argue that these rejoinders miss their target. While most admit that there is a presumption against weaseling (even Melia concedes this much $)^{4}$, they do not correctly identify the source of this presumption. I contend that the source of the presumption against weaseling is readily apparent when we consider other, more mundane cases of people engaging in weaseling behavior. It is grounded in the weasel having a conflict between two types of commitments, descriptive commitments and normative commitments. While uncovering the source of the presumption against weaseling provides support to those opposed to weaseling (it reinforces the contention that they were right all along to question its legitimacy), this is not entirely bad news for the weasel. For uncovering the source of the presumption against weaseling also serves to draw out the challenge that the weasel must meet to override this presumption, what is required to be an 'honest weasel'.

The structure of the paper is as follows. In Section 2, I present The Weasel Response to indispensability arguments in greater detail and consider responses to weaseling in the literature. I argue that these responses are not only unsatisfactory, they do not correctly identify the source of the presumption against weaseling. In the balance of the paper, Section 3 and Section 4, I develop an account that does correctly identify what underlies the presumption against weaseling. This account draws lessons from more mundane instances of weaseling behavior. It not only uncovers the presumption against such weaseling, but also reveals what is required to override this presumption. Not all weasels need be dishonest weasels.

\section{The weasel response}

At the outset of this paper, I presented a general account of The Weasel Response to indispensability arguments. Before continuing, we ought to consider a more detailed account of this response and, in particular, the activity of weaseling that underlies it.

${ }^{4}$ Melia 2000: 468. 


\section{(A) Weaseling and the indispensability argument}

A person is engaged in weaseling when she makes claims that, by her own admission, imply that she is committed to the existence of mathematical objects, but then proceeds to 'take back' this commitment. To illustrate, Melia supplies the following example: ${ }^{5}$

(1) Everyone who Fs also Gs. Except Harry-he's the one exception.

We might accuse someone who makes the above claim of simply asserting contradictory statements. That is, we might interpret them as straightforwardly asserting: "Everyone who Fs also Gs, and there is someone who Fs but doesn't G." But this would be uncharitable; it seems that we ought to interpret them as saying: "Apart from Harry, anyone who Fs also Gs." Nevertheless, Melia maintains that the original statement 'makes perfect sense'. ${ }^{6}$ We understand what the person is saying; it is a classic example of weaseling. To convey some state of affairs, the speaker 'takes back' part of what is implied in the first statement.

Not only are weaseling statements like (1) common in everyday discourse, Melia maintains that this sort of 'taking back' occurs in science:

Sometimes, in order to present our (consistent) picture of the world, it is legitimate to take back details that were asserted earlier. Nor do I believe that even this is radical. It is common practice. Whilst almost all scientists will admit that they must quantify over numbers in order to formulate their scientific theories, almost all will go on to deny that there are such things as mathematical objects. (Melia 2000: 469)

This presents a serious challenge to proponents of indispensability arguments. If Melia is correct, scientists regularly engage in weaseling (at least about mathematical objects). What is more, he maintains that this is entirely acceptable; it is common practice. Following scientists, then, it seems opponents of indispensability arguments can concede that references to mathematical objects are, indeed, indispensable to our best scientific theories while nonetheless denying

${ }^{5}$ Melia 2000: 467-8.

${ }^{6}$ Melia 2000: 468. 
that we thereby have ontological commitments to these objects. They can do so while retaining their naturalist credentials.

\section{(B) What is wrong with weaseling?}

Weaseling poses a serious threat to indispensability arguments. Responses to indispensability arguments typically target one or another particular premise. As a result, they tend to have a more narrow scope and only pose a challenge to those variants of the argument that invoke the targeted premise. ${ }^{7}$ In contrast, The Weasel Response has very broad scope. ${ }^{8}$ It grants the indispensability of mathematics to science and nonetheless rejects the conclusion that we are thereby committed to the existence of mathematical objects. It leaves open which of the other premises, in each variant of the indispensability argument, is false. Consequently, it seems equally applicable to all the various versions of indispensability arguments that have been proposed.

When we consider the broad scope of The Weasel Response, we might wonder whether it is actually too strong. It is natural to suspect that something must be amiss with this response. In what follows, I want to consider some suggestions in the literature that attempt to draw out what is amiss in this powerful (albeit quite simple) rejoinder to indispensability arguments. Although I shall argue that these analyses miss the mark, discussing them (and their shortcomings) highlights some important features of The Weasel Response.

${ }^{7}$ For example, it is common for opponents of indispensability arguments to reject Confirmational Holism. While this is generally considered to be a crucial premise of the Quine-Putnam Indispensability Argument, this objection has no grip on the Enhanced Indispensability Argument. Confirmational Holism is not included among the premises of this version of the indispensability argument. See Baker 2009: 612-3.

${ }^{8}$ Even responses to the argument that target the indispensability of mathematics to science tend not to have such a broad scope. For the relevant 'indispensability' varies with the particular indispensability argument under consideration. Some versions take this indispensability to be quite broad, e.g., to include indispensable contributions to the theoretical virtues of theories generally. (See, for example, the indispensability argument presented in Colyvan 2001.) Other versions take a more narrow reading of the sense of 'indispensability' that is important to the argument, e.g., that only indispensable explanatory contributions are relevant. (See the indispensability argument presented in Baker 2009.) 


\section{The missing paraphrases}

Critics might (and probably should) concede that the example Melia supplies in (1) illustrates that some cases of weaseling are acceptable. It is not uncommon in everyday discourse for people to express themselves with assertions that 'take back' part of what is implied in an earlier assertion. But there is an important difference between the everyday weaseling that occurs in (1) and weaseling that, according to Melia, scientists engage in when they deny commitment to the existence of mathematical objects. Whereas a non-weaseling paraphrase is available that captures the speaker's content in the former, i.e., "Apart from Harry, anyone who Fs also Gs", these paraphrases are not always available when it comes to scientists' weaseling about the existence of mathematical objects. One might argue that this absence of non-weaseling paraphrases undermines the acceptability of weaseling.

Raley (2012) criticizes weaseling along these lines, but she is hardly alone. A similar response can be found in Azzouni (2009) and Colyvan (2010). To be sure, there is something compelling about this response, but it is problematic. Knowles and Liggins (2015) maintain that this tempting response to weaseling begs the question against Melia. ${ }^{9}$ To see why, consider what Melia says in defense of weaseling. He admits that weaseling is not ideal (that it can be 'unhelpful' and 'misleading' ) 10 , which naturally raises the question, "Why engage in weaseling?" To which Melia replies:

Because sometimes we have to. Sometimes, we just cannot say what we want to say first time round. Sometimes, in order to communicate our picture of the world, we have to take back or modify part of what we said before. ${ }^{11}$

Melia contends that, in some cases, weaseling is required to communi-

${ }^{9}$ Here Knowles and Liggins are specifically addressing Raley (2012), but as discussed earlier, she is not the only critic to suggest that legitimate weaseling requires appropriate non-weaseling paraphrases. Colyvan (2010) advocates a similar position, and the same rejoinder (that his begs the question against Melia) is presented in Liggins 2012.

${ }^{10}$ Melia 2000: 468.

${ }^{11}$ Melia 2000: 468-9. 
cate our picture of the world. This does seem to invite the criticism that it would be question begging of the critic to require that scientists supply mathematics-free paraphrases to legitimize their weaseling. This is tantamount to an outright rejection of Melia's account. It is to require the very thing that Melia explicitly denies is available.

For the critic to require such paraphrases and not be guilty of begging the question against Melia, Knowles and Liggins suggest that she must "establish that every conclusion that can be articulated through weaseling can also be articulated without it". ${ }^{12}$ While this would, indeed, present a serious challenge to Melia's account, it places too large a burden on the critic. To avoid begging the question, she need only undermine Melia's support for the claim that sometimes scientists cannot convey their views without weaseling. Were the critic to supply good reason to doubt this, she would put the ball back in his court. However, whether this is a challenge that the paraphrase-demanding critic can meet is not something that I will pursue here. For, as I shall argue shortly, there is a deeper problem with weaseling that is orthogonal to this issue. But first, I want to consider another, more recent response to weaseling.

\section{The rationality of weaseling}

Rather than suggesting that the underlying worry with weaseling is the absence of non-weaseling paraphrases, Knowles and Liggins supply a different worry. They begin by questioning whether scientists really have the nominalist beliefs that Melia attributes to them and, consequently, whether they really engage in weaseling. While this would pose a problem for Melia's presentation of The Weasel Response, which presumes that almost all scientists do (or, at least, would) engage in weaseling, Knowles and Liggins are careful to note that even if most (or even all) scientists avoid weaseling, this response to the indispensability argument remains of interest. For the central issue need not turn on whether scientists are engaged in weaseling, but "whether or not they do, scientists can weasel without compromising their rationality". ${ }^{13}$

\footnotetext{
${ }^{12}$ Knowles and Liggins 2015: 3401.

${ }^{13}$ Knowles and Liggins 2015: 3410.
} 
With this alteration, Knowles and Liggins contend that the success of The Weasel Response turns on the role that mathematics plays in science. If mathematics merely plays a representational role (representing purely physical properties) in scientific practice, then scientists can rationally engage in weaseling. On the other hand, if proponents of heavy duty platonism are correct and, for example, we ought to understand physical magnitudes (mass and temperature) employed in scientific practice to be relations between concrete objects and numbers, then scientists cannot rationally engage in weaseling.

Here, then, Knowles and Liggins part company with those who demand that acceptable weaseling requires non-weaseling paraphrases. Whether weaseling is acceptable does not depend on our answer to the question "Are non-weaseling paraphrases available?" It depends on our answer to the question "Are scientists who engage in weaseling compromising their rationality?" which, in turn, depends on whether representationalism or heavy duty platonism is a more accurate reflection of scientific practice. While this is an interesting shift, it confronts a challenge similar to that which confronts the paraphrase-demanding critics. It ignores an important element of Melia's account. It ignores the very component that Knowles and Liggins suggest is ignored by those who maintain that legitimate weaseling requires non-weaseling paraphrases. For again, recall that Melia does not merely maintain that nominalist scientists happen to engage in weaseling. He maintains that, in some cases, they must engage in weaseling. This crucial element suggests a problem for the challenge raised by Knowles and Liggins. If Melia is correct that there are cases where nominalist scientists must engage in weaseling, how can it be irrational that these scientists do engage in weaseling?

To illustrate the worry, suppose that heavy duty platonism (rather than representationalism) is a more accurate reflection of scientific practice. In what sense is the nominalist scientist who engages in weaseling guilty of irrationality? We should not expect that the debate between nominalists and heavy duty platonists to resolve so strongly in favor of the latter that a nominalist scientist's adoption of the former is deemed irrational. So, the criticism of irrationality cannot lie with the adoption of nominalism itself. Rather, the irrationality must be that weaseling (while respecting their nominalism) 
does not align with the heavy duty platonism reflected in scientific practice. But, again, given that we are assuming that (a) there remain good reasons for the scientist to embrace nominalism and (b) Melia is correct that the nominalist scientist must sometimes engage in weaseling to convey her views, then while we might criticize this nominalist scientist on other grounds, it does not seem appropriate to accuse her of behaving irrationally. After all, she is simply doing what she must.

In short, Knowles and Liggins' suggestion goes in the wrong direction. If our weaseling nominalist scientist is guilty of something, it is wrong to think that the failure is one of rationality. In our example, the nominalist's failure is analogous to a person failing to 'practice what she preaches'. But, while there is a sort of consistency worry here, it is not a failure of rationality. The first step, then, is to get clear on what exactly a nominalist scientist is guilty of when she engages in weaseling.

\section{What is really wrong with weaseling?}

There does seem to be a presumption against weaseling. At the very least, weaseling is not ideal. Although some misgivings concerning weaseling might derive from the seeming contradictoriness in what is communicated, others have explored this concern. I will not pursue this line of thought here. ${ }^{14}$ Rather, I will argue that, even putting aside worries concerning what is communicated, there is another aspect of weaseling that underlies the presumption against it. To present this aspect, I begin with two observations.

\section{(A) Internal and external weaseling}

The first observation concerns a distinction between two types of weaseling, what we might call 'internal weaseling' and 'external weaseling'. To illustrate, suppose that $\mathrm{T}$ is the simple theory about Fs

${ }^{14}$ I refer the reader to Knowles and Liggins 2015. They explore (and ultimately reject) objections to weaseling along these lines. It would take us too far astray to delve into this issue here, and as we shall see shortly, there is another aspect of weaseling that accounts for the presumption against it. 
and Gs consisting of the two sentences in Melia's example: "Everyone who Fs also Gs. Except Harry-he's the one exception." Here the second sentence takes back something asserted in the first. This 'taking back' occurs in the theory. As such, it is what we might call 'internal weaseling'.

While I worry about making any sweeping generalizations about scientific theorizing, it does not seem that internal weaseling is something that the nominalist scientist engages in. When explaining experimental results and expressing their theories, scientists routinely employ mathematics. Rarely (at least in my experience) do they include as part of their theories explicit existential denials of the mathematics employed.

The nominalist scientist's weaseling occurs when she is talking about her theories. She engages in weaseling when she denies that there are the sorts of mathematical 'things' that her theories imply exist. This weaseling is not a part of her theories; it is weaseling about these theories - that certain 'things' her theories say exist do not exist. It occurs in the assertions/beliefs that the nominalist scientist has about her theories, not as a part of the theories themselves. A such, it is what we might call 'external weaseling'.

Perhaps critics could provide examples of scientific theories that include internal weaseling. Even so, the important point still stands. Though some theories might contain this weaseling, it does not seem to be the sort of thing with which scientists are terribly concerned when presenting their theories. And, more to the point, this is not the sort of weaseling that Melia is claiming scientists engage in. The weaseling with which Melia is concerned is something that occurs when nominalist scientists make assertions about their theories. It is an example of external weaseling. It occurs in the assertions/beliefs that scientists have about their theories.

\section{(B) Two senses of 'commitment'}

The second observation concerns indispensability arguments. While there are many versions of these arguments, they share the same underlying structure. They conclude that, insofar as reference to mathematical objects (numbers, sets, functions, etc.) is indispensable to science, we are committed to their existence. There has been much 
debate concerning which premises make for the strongest version of the indispensability argument, as well as the particular formulations of these premises. For my purposes, I will not venture into this well-trodden ground. It would take us too far astray. Instead, I want to consider a common statement of the conclusion of these arguments - that we are committed to the existence of mathematical objects.

What does it mean to say that we are committed to the existence of mathematical objects? While this might seem straightforward, 'commitment' in this context can have two different meanings that need to be disambiguated. To illustrate, consider the following scenario:

Private Ryan. Ryan is a private in the military who is routinely insubordinate. Despite his persistent insubordination, there is an important sense in which Ryan is committed to obeying his superiors. He incurred this commitment as a result of taking an oath of service when he enlisted (which includes a vow to obey his superiors). On the other hand, it is also true that Ryan is not committed to obeying his superiors. He routinely engages in insubordinate behavior that reflects this lack of commitment. We can even suppose that Ryan does not believe that he ought to obey his superiors, and he is quite vocal about this.

Suppose we ask the question: "Is Ryan committed to obeying his superiors?” We might answer 'yes'. When he joined the army, he took an oath of service. Among the things included in this oath is a vow to obey one's superior officers. As a result, Ryan incurred this commitment. On the other hand, we might answer 'no'. Ryan's routine (and vocal) insubordination reflects that he has no such commitment.

Have we contradicted ourselves with these answers? Clearly not, the answer 'yes' and 'no' to the query concerning Ryan's commitments depends on the sense of 'commitment' under investigation. When we answer 'yes' to the question "Is Ryan committed to obeying his superiors?" we are talking about the commitments that Ryan has in virtue of various obligations that he has acquired. We are referring to what, as a result of having taken certain vows (or similar obligation incurring activities), he is committed. It is in this sense that Ryan has a commitment to obey his superiors. When we answer 
'no', we are talking about the commitment that Ryan lacks in virtue of his practices. We are referring to what, in practice, he is committed. It is in this sense that Ryan lacks commitment to obey his superiors.

To disambiguate the above uses of the term 'commitment', we can talk about an individual's 'normative commitments' and 'descriptive commitments'. Normative commitments refer to those commitments incurred as a result of engaging in activities that generate certain obligations, e.g., vows and oaths. This reflects the sense of 'commitment' operative in the claim that Private Ryan has a commitment to obey his superiors, which he is failing to uphold. On the other hand, descriptive commitments refer to what, in practice, an individual is committed. This is the sense of 'commitment' operative in the claim that Private Ryan is not committed to obeying his superiors; his persistent insubordination reflects that he has no such commitment.

\section{(C) Ontological infidelity}

Just as we can distinguish between Ryan's descriptive and normative commitments when it comes to obeying his superiors, we can also distinguish between his descriptive and normative ontological commitments. By 'descriptive ontological commitments', we are referring to what, in practice, Ryan is committed. Just as we look to his practices, what he does and says, to determine his descriptive commitments in other contexts (e.g., whether they reflect a commitment to obey his superiors), we look to what Ryan does and says to determine his descriptive ontological commitments. To the extent that Ryan expresses a commitment to the existence of electrons, e.g., Ryan expressly says that he believes that there are such things and his behavior reflects this belief, this is strong evidence that Ryan is, in fact, descriptively committed to the existence of electrons. In addition to Ryan's descriptive ontological commitments, we can also talk about his normative ontological commitments. Here we are referring to the commitments that Ryan has as a result of engaging in activities that generate certain ontological obligations.

At this point, a question naturally arises about Ryan's normative ontological commitments. In the case of Ryan's normative 
commitment to obey his superiors, it is clear what generated this commitment. Upon enlisting, Ryan took an oath of service that gave him this commitment. But what generates a person's normative ontological commitments? From where do these commitments derive their normativity? What makes it the case that a person ought to accept/believe that something exists?

Much like other normative commitments, the sources of normativity when it comes to ontological commitments are varied. Consider, for example, avowed fundamentalist Christians. Insofar as they really do adopt a fundamentalist position towards Christian doctrine, they ought to accept the existence of angels. This normative ontological commitment comes from their avowed fundamentalism, though it might conflict with their descriptive ontological commitments (their practices might not reflect this commitment).

That the adoption of religious views can generate corresponding normative ontological commitments is not terribly surprising, but this is hardly the only source of such commitments. The adoption of certain scientific views, much like the adoption of religious views, can impart normative ontological commitments. Consider the naturalist position that we should look to science and, in particular, our best scientific theories as our best guide to what exists. ${ }^{15}$ Scientists (and other naturalistically minded individuals) who adopt this naturalist position are normatively ontologically committed to the existence of molecules and electrons. They might also, if proponents of indispensability arguments are correct, have ontological commitments to the existence of mathematical objects. These are normative ontological commitments. They concern what these naturalistically minded individuals ought to accept as existing. Of course, what their descriptive ontological commitments are is a different matter.

\footnotetext{
${ }^{15}$ It is worth noting that this is not the only naturalist view concerning ontology that one might adopt. For example, one might maintain that we should look to scientific practice generally (rather than merely to scientific theories) to determine what exists or that our ontology should be limited to those things that are manipulatable in scientific experiments. The former is suggested in Maddy 1997, and the latter in Hacking 1983. Here I limit my attention to the sort of naturalism common to indispensability arguments, i.e., one that maintains that our best scientific theories are our best guide to what exists.
} 


\section{(D) The descriptive/normative distinction in practice}

In the next section, I will argue that distinguishing between descriptive and normative commitments sheds light on what is wrong with weaseling. But first, I want to consider the overlap that can arise between these types of commitments in scientific practice, as well as the broader role that this distinction can play in ontological discourse.

One concern that might be raised is that, unlike the case of Private Ryan, it can often be difficult to tease apart descriptive commitments and normative commitments when it comes to science. Take, for example, a scientist whose everyday practice is conducted in a manner that appears to assume the truth of some theory, $\mathrm{T}$. She uses the theory to communicate with her colleagues and explain various phenomena. Suppose that in these explanations, reference to mathematical objects is indispensable and, in particular, that the role of mathematics in these explanations is not merely a simplifying (or representational) role. With this scenario, one might raise the following challenge, "Doesn't the scientist's use of $T$, which involves a non-representational invocation of mathematical objects to explain phenomena, normatively commit her to the existence of these objects?"16

The short answer to this challenge is "no". In the above example, we are still only talking about commitments that reflect to what, in practice, an individual is committed. These are merely descriptive commitments. To attribute to the scientists some normative commitment, we need to identify the normative source of this commitment. Were the scientist to adopt the ontological naturalism described earlier, i.e., the view that our best scientific theories are our best guide to what there is, this would supply compelling grounds for maintaining not only that the scientist has a descriptive commitment to the existence of mathematical objects but a normative one, as well. Nonetheless, absent adopting this ontological naturalism (or some similar view) we are missing the source of normativity required to ground normative commitments. It is the adoption of this

\footnotetext{
${ }^{16}$ I would like to thank an anonymous referee for bringing this concern to my attention.
} 
naturalist view that grounds the 'ought' in the claim that she ought to have such ontological commitments.

Here an analogy might prove instructive. Consider the parent who conveys moral lessons through the use of myths and fables, which reference imaginary or idealized beings. We can suppose that the parent (like our working scientist) takes herself to be expressing truths - albeit moral truths. To the extent that these beings are, indeed, indispensable to her practices (she finds an indispensable need to invoke them to convey the appropriate moral lessons), we might rightly ascribe to her a descriptive commitment to their existence. Nonetheless, it would be a mistake to ascribe to her any normative ontological commitment to these beings. For again, what is the source of this normativity? It will not do to simply point out that they are indispensable to a theory the parent employs in practice. It needs to be the case that the parent adopts a position that gives ontological authority to that theory (much like our naturalist scientist who takes our best scientific theories to be our best guide to what exists). Absent some such position, while it might be apt to ascribe descriptive commitments to these idealizations (they serve an indispensable role in their practice), we would be lacking suitable grounds to ascribe normative commitments to them.

One more clarification is worth highlighting before moving on. The preceding example concerning working scientists (indispensably invoking mathematical objects when engaging in scientific practice) was presented in manner that aimed to support platonism (we assumed that the mathematics invoked was, indeed, explanatorily indispensable). In which case, there is a reasonably strong argument to be made that this scientist is descriptively committed to the existence of these mathematical objects. Of course, she may deny such commitments; in which case, there would be conflict among her descriptive commitments. When we consider her practices, some elements (her use of T) might indicate descriptive commitments to the existence of mathematical objects and other elements (her verbal espousals) indicate a lack of such commitments. While there is much to explore in this sort of conflict, it is not the sort of conflict that is central to our concern here. The conflict that is relevant, what I shall argue is central to weaseling, is not a conflict between one's descriptive commitments. Rather, what is indicative of weaseling 
(analogous to the Private Ryan's situation) is a conflict between one's descriptive commitments and normative commitments.

This brings me to the second point that I want to highlight in this section. These types of commitments, along with the conflict that can arise between them, can play a broader role in ontological discourse. It can aid in avoiding potential confusions that might arise in ontological debates. Take, for example, the debate concerning whether scientists are committed to the existence of mathematical objects. Maddy (1997) argues that if we look to scientific practice, we see that scientists are no more committed to these 'things' than to other questionable ontological posits of scientific theories, e.g., infinitely deep oceans or frictionless planes. Proponents of the indispensability, e.g., Colyvan (2001), seem to make the opposite claim; scientists do have these commitments.

It might seem, then, that we have two conflicting answers to the question: 'Are scientists committed to the existence of mathematical objects?' Maddy says 'no', but proponents of indispensability arguments say 'yes'. Just as with the Private Ryan scenario, however, the conflict between these seemingly contradictory answers dissolves when we are careful to distinguish whether we are talking about descriptive or normative commitments. The negative answer to the above question, insofar as it focuses on what is exemplified in the practices of scientists (and what scientists themselves would presumably espouse), concerns their descriptive ontological commitments. Whereas the affirmative answer, which is supplied by proponents of indispensability arguments, focuses on what naturalist scientists ought to endorse; it focuses on their normative ontological commitments. Given their commitment to ontological naturalism (that our scientific theories are our best guide to what exists) and the indispensability of mathematical objects to our scientific theories, scientists are normatively ontologically committed to the existence of these objects.

Of course, there is some tension that arises with the preceding 'yes' and 'no' answers to the question of whether scientists are committed to the existence of mathematical objects. Given that the affirmative answer refers to normative commitments and the negative answer to descriptive commitments, there is no outright contradiction here - nonetheless, there is a potential conflict. For a 'yes' and 
'no' answer along these lines suggest, much like in the case of Private Ryan, that these scientists' descriptive commitments do not align with their normative commitments. ${ }^{17}$ This brings us to the problem underlying weaseling.

\section{(E) The dishonest weasel}

When scientists engage in weaseling, they concede that references to mathematical objects are, indeed, indispensable to our best scientific theories while nonetheless deny that we thereby have any ontological commitments to these objects. As noted earlier, this weaseling is not internal to scientific theories. It occurs in the assertions/beliefs that scientists have about their theories. To put this in terms of descriptive/normative commitments, the weaseling scientist is expressing the absence of descriptive ontological commitments to the existence of mathematical objects. The problem is that this generates a potential conflict between her descriptive and normative ontological commitments. What, in practice, she endorses (or denies) exists might not reflect what she ought to endorse (or deny) exists.

Now, I say that weaseling scientists have a 'potential' conflict between their descriptive and normative commitments. Whether there is, in fact, any conflict depends on the presumption that they embrace the naturalist view that our best scientific theories are our best guide to what exists. This ontological naturalism, together with the conclusion that reference to mathematical objects is indispensable to our best scientific theories, provides the scientist with a normative ontological commitment to the existence of mathematical objects. If the weaseling scientist rejects this naturalism, there is no conflict; but this is not a surprising result. Such a scientist would be like the philosopher who engages in academic study of theological accounts but rejects their ontological authority. For such a philosopher, there is no conflict between her descriptive and normative ontological

\footnotetext{
${ }^{17}$ This misalignment nicely captures the sort of 'intellectual dishonesty' with which opponents of indispensability arguments are sometimes charged when they deny the existence of the mathematical objects referred to in our best scientific theories. The clearest statement of this charge comes from Putnam who identifies this dishonesty with Quine's criticism of “denying the existence of what one daily presupposes”. See Putnam 1971: 57 and Quine 1948: 28.
} 
commitments. Insofar as she rejects the ontological authority of these accounts, they do not provide her with any normative ontological commitments.

The interesting case, then, is that of the weaseling scientist who accepts our scientific theories to be ontological authorities, who embraces the view that these theories are our best guide to what exists. This is the scientist for whom indispensability arguments pose a problem. Given her naturalism, she is normatively ontologically committed to the existence of mathematical objects. After all, she concedes that these objects are indispensable to our best scientific theories and accepts the ontological authority of these theories. What her weaseling reflects is her lack of descriptive ontological commitment to their existence.

The descriptive/normative distinction concerning commitments allows us to identify what underlies the worry with The Weasel Response to indispensability arguments. What is worrisome in this case is that, at least for naturalistically inclined scientists, there is a conflict between their descriptive and normative ontological commitments. The presumption against such weaseling, then, is much like the presumption against Ryan's insubordination. In each of these cases, the commitments that the individual, in practice, endorses (or denies) do not reflect those he/she ought to endorse (or deny). Where the force of this 'ought' comes from the individual having engaged in activities, e.g., having taken certain oaths, vows, or endorsement of certain positions, that confer the commitments that she is failing to respect.

\section{A guide to weasel hunting}

We have identified the source of unease that underlies the presumption against scientists weaseling. It is similar to the presumption against Private Ryan's insubordination. These practices exemplify a misalignment of an individual's descriptive and normative commitments. The scientist's weaseling concerns ontological commitments whereas Private Ryan's misaligned commitments concern military commitments, but the underlying problem remains the same. The commitments that the individual, in practice, endorses (descriptive commitments) do not reflect those he/she ought to endorse (norma- 
tive commitments). There is, in general, a presumption against this kind of misalignment.

It is important to note, however, that our analysis only supplies an account of the presumption against weaseling. It is one thing to say that there is, in general, a presumption against some practice and another to say that it is actually wrong. It does not take much creativity to construct scenarios according to which the presumption against insubordination is overridden. That being said, our analysis does suggest that the burden of proof (much like in the case of Private Ryan) is on the weasel. In this section, I consider this 'burden of proof' challenge in more detail. But first, I want to take a moment to consider how the preceding analysis, what I shall call the 'Descriptive/ Normative Misalignment Account' (The DNM Account), provides a better account of the presumption against weaseling than those discussed in Section 4.

\section{(A) Better account of weaseling}

Consider first Knowles and Liggins' suggestion that the legitimacy of weaseling comes down to whether scientists can weasel without compromising their rationality. As we saw, it seems a mistake to conceptualize the worry with weaseling as concerning rationality. If Melia is correct, then sometimes anti-Platonist scientists must engage in weaseling to convey their views. In which case, it is dubious to maintain that this weaseling is irrational. Of course, one could identify the irrationality in question with the adoption of anti-Platonism itself, but this, too, seems dubious. It is one thing to argue that Platonism is superior to anti-Platonism; it is another to argue that embracing the latter is irrational. To rest the irrationality of scientists' weaseling on establishing the irrationality of adopting antiPlatonism, places too heavy a burden on the Platonist.

The DNM Account reinforces the contention that it is a mistake to think that the presumption against weaseling is a matter of rationality. On this account, the presumption against weaseling comes down to a misalignment between the weasel's descriptive and normative commitments. Such misalignments need not be indicative of irrationality. Consider, again, the case of Private Ryan. There is a misalignment between his normative and descriptive commitments. 
The commitment to obey his superior officers (a normative commitment) does not align with to what, in practice, he is committed (descriptive commitments). While there is certainly a presumption against this misalignment, it is too quick to think that the individual is acting irrationally. Not all cases of insubordination (even insubordination similar to Private Ryan's) are cases in which the individual is acting irrationally. In fact, one might — similar to Melia's contention concerning scientists' weaseling - argue that there are cases in which one must engage in insubordination. Prudential or moral concerns might require engaging in this activity that, other things being equal, there is a presumption against. (For example, suppose Private Ryan's superiors routinely issued immoral orders, e.g., demanding that Ryan execute non-combatants. Were this the case, one might argue that insubordination is not only permissible, it is required.)

What about the objection to weaseling suggested by Raley? The crux of her objection is that weaseling is only acceptable when there are appropriate non-weaseling paraphrases. While initially compelling, this objection seems to ignore a crucial component of Melia's account - that, in some cases, there simply are no non-weaseling paraphrases available. To require these paraphrases, then, seems question begging. Notice that while the contention that sometimes there simply are no non-weaseling paraphrases available presents a challenge for Raley's account of the presumption against weaseling, it is not a problem on the DNM Account. This account can readily accept the conclusion that, with some scientific theories, there simply are no non-weaseling paraphrases available. This only serves to emphasize the extent of the underlying problem with weaselingthat it might not always be the case that scientific theories can be expressed in a way that respects scientists' descriptive commitments. And, consequently, these scientists' normative ontological commitments cannot be brought in line with their descriptive ontological commitments.

\section{(B) The weasel's burden}

The DNM Account provides an account of the presumption against weaseling that avoids the shortcomings of accounts that locate this concern as a matter of irrationality or missing paraphrases. It is 
worth emphasizing, however, that the DNM Account only establishes a presumption against weaseling. Perhaps weaseling, as a response to indispensability arguments, can be shown acceptable. How might one establish this?

Here, again, we might draw insight from the case of Private Ryan. How might Ryan respond to the challenge that his descriptive commitments do not match his normative commitments? It seems that there are two possible responses: (1) show that, contrary to appearances, there is not actually a misalignment between these commitments, or (2) establish that this misalignment is acceptable.

The first response does not, in general, appear very promising. Given that Ryan's insubordination is not in question, the only way to establish (1) would be to show that he does not, in fact, have a normative commitment to obey his superiors. We might concede this to be the case if the grounding of this commitment were called into question, e.g., Ryan's oath of service was taken under duress. Putting aside such situations, it is unclear how Ryan could show that there is not, contrary to appearances, a genuine misalignment in his descriptive and normative commitments.

Consequently, it seems that the most promising response to the challenge posed by the DNM Account is not to deny the misalignment in question, but to establish that it is acceptable. This would be the case were there a countervailing normative commitment that mitigated (if not over-ruled) Ryan's normative commitment to obey his superiors. One obvious candidate would be the commitment to certain moral principles that might otherwise be violated. If Ryan's superiors were issuing immoral orders, this would constitute a good response to the general presumption against insubordination on the DNM Account. ${ }^{18}$ This response does not deny that there is a misalignment between Ryan's descriptive and normative commitments. It embraces this misalignment and suggests that, nonetheless, it is acceptable. There is another stronger normative commitment with which Ryan's descriptive commitments are in alignment.

\footnotetext{
${ }^{18}$ I expect that there are other normative commitments that could overrule the deserter's commitment to defend their country, but what other commitments could serve this 'overruling role' is undoubtedly a matter of some controversy. That moral commitments can play this role seem relatively uncontroversial.
} 
To establish the acceptability of his insubordination, then, it seems that the burden is on Ryan to show that there is a countervailing normative commitment that mitigates the misalignment of the specific normative and descriptive commitments that are in tension. This does not seem terribly contentious. Though they might not put the point in these terms, we might well expect ethicists to make a similar demand. What is more, we can extend this resolution to the descriptive/normative mismatch that arises with Private Ryan to address the mismatch that arises with the weaseling scientist. The weaseling scientist (much like Private Ryan) has a mismatch in her descriptive and normative commitments. And, again, just like Private Ryan, there seems to be two ways to resolve this tension: (1) show that, contrary to appearances, there is not actually a misalignment between these commitments or (2) establish that this misalignment is acceptable.

Here, too, the first option does not appear very promising. Neither the weasel's acceptance that reference to mathematical objects is indispensable to science nor her subsequent rejection of ontological commitment to these objects is in question. As such, the only way to establish (1) would be to show that, contrary to appearances, the weasel does not have the misaligned normative commitment. In other words, we would need to show that she does not have a (normative) ontological commitment to the existence of those things that are indispensable to our best scientific theories.

One way to establish this result is simply to reject that we look to science as our best guide to what exists. However, if this is the resolution to the challenge posed by the DNM Account, then it turns out that 'The Weasel Response' to indispensability arguments is not really that interesting. There only appeared to be tension here because we mistakenly attributed to someone (the scientist) a position that embraced the ontological authority of our best scientific theories. The scientist in this case is no more engaged in 'weaseling' than the philosopher who studies some religion but rejects its ontological authority. Insofar as the religion's texts and practices do not carry any ontological weight (for her), she is hardly engaged in intellectual dishonesty when she disavows their supposed existential implications.

To abandon the ontological authority of science, however, seems an extreme response. While it would immunize our scientist from 
the charge of weaseling, it comes at a high cost. The scientist does not have a normative ontological commitment to the existence of mathematical objects because she does not accept the ontological authority of science. I suspect that few opponents of the indispensability argument would want to go this far. A more tempered response would be to retain the position that science-and, in particular, our best scientific theories - are our best guide to what exists. One might nonetheless contend that while the sentences of our theories entail the existence of mathematical objects, the content of our best scientific theories is not always the content of the sentences used to express it. ${ }^{19}$ In this way, one might accept that our best scientific theories remain our best guide to what exists while rejecting the ontological authority of their formulations.

The above response, henceforth the 'Restricting Ontology to Content Response' or 'ROC Response', has the virtue of retaining a naturalist commitment to the ontological authority of scientific theories while rejecting the conclusion that this generates normative ontological commitments to the existence of mathematical objects. If successful, this would show that, contrary to appearances, the weaseling scientist does not actually have the misaligned normative commitment in question; she does not have a normative ontological commitment to the existence of mathematical objects.

While I can see the attraction of the ROC Response, it is not without problems. It not only requires a detailed account of the content of theories (which is distinct from the content of the sentences used to express them), it also requires that this content (whatever it is) does not involve indispensable reference to mathematical objects. This last point is worth emphasizing. For what is interesting about the ROC Response is that it must accommodate especially troublesome cases, where there are no available paraphrases of a theory that excise reference to mathematical objects. In such cases, we are still supposed to be able to separate the content of the theory from the sentences used to express it. ${ }^{20}$ But I will not pursue these complica-

19 This position is suggested in Melia 2000: 472-5. See also Knowles and Liggins 2015: 3399.

${ }^{20}$ When alternative paraphrases are available, it seems natural to identify the content of mathematically laden propositions with the content of these paraphras- 
tions here. Given our central concern, i.e., exploring The Weasel Response to indispensability arguments, there is a deeper worry.

As a defense of weaseling, the ROC Response undermines what seemed interesting about The Weasel Response in the first place. It turns weaseling into a more elaborate means of simply rejecting commitment to versions of naturalism that grant ontological authority to the propositions expressing our scientific theories. Of course, debate will continue whether the content of scientific theories to which Melia is referring - that content that is not adequately captured by their mathematics laden formulations - can really dispense with reference to mathematical objects. ${ }^{21}$ But we have abandoned what seemed interesting about The Weasel Response. What originally seemed to be an interesting, new rejoinder to indispensability arguments, turns out to merely be a façade for a familiar objection. We have retreated to the familiar ground of quibbling over what sort of naturalism to embrace. ${ }^{22,23}$

What seemed interesting about weaseling was that the weasel

es. Absent such paraphrases, the challenge of providing an account of the content of sentences (distinct from the content of the sentences used to express them) is more pronounced. As noted earlier, these are the sorts of cases in which Melia seems particularly concerned. They are one's in which a scientist must (it seems) engage in weaseling.

${ }^{21}$ If reference to mathematical objects really is indispensable to certain scientific explanations, as Baker $(2000,2005)$ argues, then it may be that the content of our theories cannot entirely dispense with reference to mathematical objects.

${ }^{22}$ It was always open to opponents of indispensability arguments to reject whatever version of naturalism is invoked in these arguments. This is no more novel than rejecting the argument's dependence on a particular criterion of ontological commitment (e.g., Quine's Criterion).

${ }^{23}$ There are a number of long-standing debates concerning more nuanced versions of naturalism that aim to limit the ontological authority of scientific theories in troublesome cases (e.g., where our theories would otherwise commit us to ontologically undesirable things). Consider, for example, attempts to divide scientific theories according to observable/unobservable or instrumental/noninstrumental criteria, with the aim of limiting the ontological authority of these theories to their observable/non-instrumental components. These attempts received a great deal of attention in the development and critique of logical positivism. See, for example, Putnam (1962) and Maxwell (1962) who critique these attempts, and Van Fraassen (1980) who defends this distinction. 
seemed to grant ontological authority to scientific theories simpliciter. The Weasel Response to indispensability arguments did not require that we reject the ontological authority of formulations of these theories. In fact, weaseling seems at odds with this sort of move. For what is characteristic of weaseling is the behavior of taking something back. If no ontological authority is granted to the formulations of our scientific theories in the first place, then there is no taking back this authority in troublesome cases. There is no weaseling. For those, like myself, who think there is something interesting about weaseling, that it really does constitute a 'taking back', the ROC Response is not a good defense of weaseling. In attempting to defend weaseling, it abandons the heart of the view - it abandons the weaseling!

As with Ryan's insubordination, it seems that he more promising response to the misalignment in descriptive/normative commitments that arises with weaseling is the second option - establish that this misalignment is acceptable. The weaseling scientist needs to establish that there is a countervailing normative commitment that mitigates the misalignment of her normative and descriptive commitments. Were there such a countervailing normative commitment, this absolves the weasel of the charge of intellectual dishonesty. For, in this case, she accepts the ontological authority of our best scientific theories and that this ontic naturalism provides her with normative commitments to the existence of mathematical objects. After all, she concedes that these objects are, indeed, indispensable to our best scientific theories. But the fact that her practices do not reflect these commitments, i.e., that her descriptive commitments do not align with her normative commitments, is not objectionable. Her integrity in this case is preserved insofar as her descriptive commitments are in line with a countervailing normative commitment.

Of course, this naturally raises the following question: What might the requisite countervailing normative commitment be? What normative commitment is there that can serve the same role overriding the presumption against weaseling as ethical commitments play in overriding the presumption against Private Ryan's insubordination? The task of supplying such a commitment is a challenge that the weaseling scientist must meet. I will not venture to supply one here. My aim in this work is more modest - to get clear on what underlies the presumption against weaseling and what is required to override this presumption. 
I shall leave it to the proponents of The Weasel Response to meet this challenge. Let me close, however, by pointing out that providing the requisite countervailing normative commitment — one that can override the presumption against weaseling - is a difficult task.

Keep in mind that this countervailing commitment must be a normative commitment. It would not suffice to merely show that the weaseling scientist embraces some commitment that leads her to reject commitment to mathematical objects, despite their indispensability to our best scientific theories (e.g., that she only commits herself to the existence of non-abstract objects). Were this merely a commitment that she endorses (and is reflected in her practices), this would only establish that it is a descriptive commitment. But this does nothing to resolve the presumption against weaseling. It only serves to reinforce what we already know - that she is engaged in weaseling! Her descriptive commitments, which lead her to reject the existence of mathematical objects, do not align with her normative commitments (arising from her acceptance of the ontological authority of our best scientific theories) that direct her to accept the existence of these objects.

To legitimize her weaseling, we require that there is some overriding normative commitment that recommends rejecting the (normative) commitment to the existence of mathematical objects. In other words, the commitment in question must be one that she ought to endorse. What is more, unless she wishes to sacrifice her naturalist credentials, this normative commitment ought to come from science. It ought to be grounded in the very naturalism that gave rise to the weasel's predicament (the descriptive/normative conflict), which accepts the ontological and epistemic authority of science and, in particular, our best scientific theories. Supplying this overriding, naturalistically grounded normative commitment is a non-trivial task. Nonetheless, this is not entirely bad news for the weasel. The DNM Account supplies a path towards being an 'honest weasel'; it remains to the weasel to walk it.

\section{Conclusion}

The Weasel Response to indispensability arguments has drawn much attention. Not only is this an attractive response insofar as it sidesteps 
long-standing debates about whether (and to what extent) mathematical objects really are indispensable to scientific theories, but as Melia points out, there are grounds for thinking that weaseling is something that nominalist scientists must engage in. Despite its attractiveness, however, there is something troubling about the 'taking back' that occurs in weaseling. Some object that, in order to engage in weaseling, the weasel must be able to provide non-weaseling paraphrases. Others object that, to the extent that there is something wrong with weaseling, it constitutes a failure of rationality. I argued that these analyses of the presumption against weaseling are problematic. Instead, I presented an alternative explanation, The Descriptive/Normative Misalignment Account (The DNM Account).

The DNM Account provides an account of the intellectual dishonesty that seems to underlie weaseling. The worry is the same as that with Private Ryan's insubordination, where his normative commitments (those incurred as a result of engaging in certain obligation incurring activities) do not reflect his descriptive commitments (those endorsed in his practices). The presumption against weaseling is the same as the presumption against Private Ryan's insubordination, i.e., there is a descriptive/normative misalignment in his commitments. What determines whether this presumption is overridden is also the same. It comes down to whether there is an overriding normative commitment that legitimizes the underlying misalignment.

What we need to legitimize scientific 'weaseling' is an overriding normative commitment, one that aligns with (and thereby excuses) the weasel's descriptive commitments. While it is easy to see what overriding normative commitments might excuse the descriptive/ normative misalignment that occurs in cases like Private Ryan's insubordination (a number of ethical commitments could play this role), matters are less clear what the overriding normative commitment would be that excuses the misalignment that arises with weaseling. To make matters worse, the normative commitment in question should - assuming that the weaseling scientist wants to retain his/her naturalist credentials - come from science.

If scientific practice does, indeed, exemplify weaseling (a point which remains the subject of some debate), we might well suspect that there must be some scientifically grounded, normative commitment that licenses the descriptive/normative misalignment that 
underlies weaseling. But, of course, it is one thing to suspect that there is some such commitment; it is another to actually supply it. The case needs to be made. Without knowing what this overriding normative commitment is, the presumption against weaseling remains in place.

Patrick Dieveney Department of Philosophy California State University, Long Beach Patrick.dieveney@csulb.edu

\section{References}

Azzouni, Jody. 2009. Evading truth commitments: the problem reanalyzed. Logique \& Analyse 206: 139-76.

Baker, Alan. 2005. Are there genuine mathematical explanations of physical phenomena? Mind 114: 223-38.

Baker, Alan. 2009. Mathematical explanation in science. British Journal for the Philosophy of Science 60: 611-33.

Colyvan, Mark. 2001. The Indispensability of Mathematics. New York: Oxford University Press.

Colyvan, Mark. 2010. There is no easy road to nominalism. Mind 119: 285306.

Hacking, Ian. 1983. Representing and Intervening. Cambridge: Cambridge University Press.

Knowles, Robert. 2015. Heavy duty Platonism. Erkenntnis 80: 1255-70.

Knowles, Robert; and Liggins, David. 2015. Good weasel hunting. Synthese 192: 3397-412.

Leng, Mary. 2002. What's wrong with indispensability? Synthese 131: 395-418.

Liggins, David. 2012. Weaseling and the content of acience. Mind 121: 997 1005.

Lyon, Aidan; and Colyvan, Mark. 2008. The explanatory power of phase spaces. Philosophia Mathematica 16: 227-43.

Maddy, Penelope. 1992. Indispensability and practice. The Journal of Philosophy 89: 275-89.

Maddy, Penelope. 1997. Naturalism in Mathematics. Oxford: Clarendon Press.

Maxwell, Grover. 1962. The ontological status of theoretical entities. In Minnesota Studies in the Philosophy of Science. Minneapolis: University of Minnesota Press.

Melia, Joseph. 2000. Weaseling away the indispensability argument. Mind 109: 455-80.

Melia, Joseph. 2002. Response to Colyvan. Mind 111: 75-80.

Pincock, Christopher. 2004. A revealing flaw in Colyvan's indispensability 
argument. Philosophy of Science 71: 61-79.

Putnam, Hilary. 1971. Philosophy of Logic. New York: Harper \& Row Publishers.

Putnam, Hilary. 1962. What theories are not. In Logic, Methodology, and

Philosophy of Science, ed. by E. Nagel, P. Suppes and A. Tarski. Stanford: Stanford University Press.

Quine, W.V. 1948. On what there is. Review of Metaphysics 2: 21-38.

Raley, Yvonne. 2012. Why the weasel fails. Philosophia Mathematica 20: 339-45.

Saatsi, Juha. 2011. The enhanced indispensability argument: representational versus explanatory role of mathematics in science. British Journal for the Philosophy of Science 62: 143-54.

Sober, Elliott. 1993. Mathematics and indispensability. The Philosophical Review 102: 35-57.

van Fraassen, Bas. 1980. The Scientific Image. New York: Oxford University Press. 